Review Article

\title{
Current Innovations in Endoscopic Therapy for the Management of Colorectal Cancer: From Endoscopic Submucosal Dissection to Endoscopic Full-Thickness Resection
}

\author{
Shintaro Fujihara, ${ }^{1}$ Hirohito Mori, ${ }^{1}$ Hideki Kobara, ${ }^{1}$ \\ Noriko Nishiyama, ${ }^{1}$ Tae Matsunaga, ${ }^{1}$ Maki Ayaki, ${ }^{1}$ Tatsuo Yachida, ${ }^{1}$ Asahiro Morishita, ${ }^{1}$ \\ Kunihiko Izuishi, ${ }^{2}$ and Tsutomu Masaki ${ }^{1}$ \\ ${ }^{1}$ Department of Gastroenterology and Neurology, Faculty of Medicine, Kagawa University, 1750-1 Ikenobe, \\ Miki-cho, Kita-gun, Kagawa 761-0793, Japan \\ ${ }^{2}$ Department of Gastroenterological Surgery, KKR Takamatsu Hospital, Kagawa, Japan
}

Correspondence should be addressed to Shintaro Fujihara; joshin@med.kagawa-u.ac.jp

Received 30 January 2014; Revised 11 April 2014; Accepted 14 April 2014; Published 30 April 2014

Academic Editor: Hirotoshi Kobayashi

Copyright (C) 2014 Shintaro Fujihara et al. This is an open access article distributed under the Creative Commons Attribution License, which permits unrestricted use, distribution, and reproduction in any medium, provided the original work is properly cited.

\begin{abstract}
Endoscopic submucosal dissection (ESD) is accepted as a minimally invasive treatment for colorectal cancer. However, due to technical difficulties and an increased rate of complications, ESD is not widely used in the colorectum. In some cases, endoscopic treatment alone is insufficient for disease control, and laparoscopic surgery is required. The combination of laparoscopic surgery and endoscopic resection represents a new frontier in cancer treatment. Recent developments in advanced polypectomy and minimally invasive surgical techniques will enable surgeons and endoscopists to challenge current practice in colorectal cancer treatment. Endoscopic full-thickness resection (EFTR) of the colon offers the potential to decrease the postoperative morbidity and mortality associated with segmental colectomy while enhancing the diagnostic yield compared to current endoscopic techniques. However, closure is necessary after EFTR and natural transluminal endoscopic surgery (NOTES). Innovative methods and new devices for EFTR and suturing are being developed and may potentially change traditional paradigms to achieve minimally invasive surgery for colorectal cancer. The present paper aims to discuss the complementary role of ESD and the future development of EFTR. We focus on the possibility of achieving EFTR using the ESD method and closing devices.
\end{abstract}

\section{Introduction}

Endoscopic submucosal dissection (ESD) is accepted as a minimally invasive treatment for early gastric cancer, but technical difficulties and an increased rate of complications have limited its use in the colorectum. ESD enables the en bloc resection of a specimen, but complications (mainly perforation and bleeding) are more frequently associated with ESD compared with endoscopic mucosal resection (EMR) $[1,2]$. The balance between avoiding perforation and resecting a specimen sufficiently deep to permit accurate histopathological assessment is difficult to achieve. Due to the limitations of endoscopic techniques, a significant proportion of patients with large colonic polyps are referred for surgery [3].

In some cases, endoscopic treatment alone is insufficient for disease control, and laparoscopic surgery is required. The combination of laparoscopic surgery and endoscopic resection represents a new frontier in cancer treatment. Recent developments in advanced polypectomy and minimally invasive surgical techniques will enable surgeons and endoscopists to challenge current practice in colorectal cancer treatment.

In particular, endoscopic full-thickness resection (EFTR) of the colon might decrease the postoperative morbidity and 
mortality associated with segmental colectomy while enhancing the diagnostic yield compared to current endoscopic techniques. However, closure is necessary after EFTR and natural transluminal endoscopic surgery (NOTES). Endoscopic clips are often used for small mucosal defects but are not a suitable choice for large mucosal defects. Nonsurgical closure of the gastrointestinal wall using an over-the-scope clip (OTSC) (Ovesco, Tübingen, Germany) may be desired for inflammatory or neoplastic fistulae or iatrogenic perforations. Many endoscopic closure devices have undergone testing and evaluation in bench and animal models for use in minimally invasive surgical treatment and NOTESassociated procedures, including EFTR.

The present paper aims to discuss the complementary role of the ESD and the future development of EFTR. We focus on the possibility of achieving EFTR using the ESD method and closing devices.

\section{ESD in the Colon}

2.1. Indications for and Outcomes of Colorectal ESD. The specific indications for colorectal ESD, as recommended by the Colorectal ESD Standardization Implementation Working Group $[4,5]$, includes large-sized (>20 $\mathrm{mm}$ in diameter) lesions for which en bloc resection using snare EMR is difficult, including nongranular types of lateral spreading tumors (particularly those of the pseudodepressed type), lesions presenting type VI pit patterns, carcinoma with submucosal infiltration of less than 1000 microns, large depressed-type lesions, and large elevated lesions suspected to be carcinoma. Additional indications for ESD include mucosal lesions with fibrosis related to biopsy; sporadic tumors in chronic inflammation, such as in ulcerative colitis; and local residual carcinoma after endoscopic resection that fulfills the aforementioned criteria. An additional, often-cited indication for ESD is adenoma displaying a nonlifting sign.

ESD is not as widely performed in the colorectum compared with gastric ESD, even in Japan, because of the greater technical difficulty due to the anatomical features of the colon, including its longer length, narrower lumen, extensive flexion, and thinner walls, which increase the duration of the procedure and the risk of perforation [2, 4, 6-11].

Colorectal ESD remains more technically challenging than esophageal and gastric ESD for the following reasons. First, the anatomical features of the large intestine, including a long luminal organ with many folds and flexions, mean that the endoscope cannot be easily manipulated to reach certain lesions. Additionally, the intestinal wall is thin and easy to perforate. Importantly, the longer operation time increases the amount of air in the abdomen, causing greater paradoxical movement of the endoscope. The paradoxical movement of the endoscope during ESD due to the winding nature of the colorectum causes coagulation in the muscularis propria. This situation specifically occurs in the case of tumors located in the cecum, up to the descending colon. Second, peritonitis may occur if stool in the large intestine leaks through a perforation and into the abdominal cavity [12].
Table 1 summarizes the outcomes of colorectal ESD using previous reports from single-institution studies [7, 13-31]. The outcomes of colorectal ESD, as summarized from previous reports from multicenter studies, reveal rates of en bloc resection (endoscopic) and complete en bloc resection (histological) of $88.8 \%$ and $83.8 \%$, respectively $[2,5]$. In another study, Farhat et al. [32] reported en bloc resection (endoscopic) and complete en bloc resection (histological) rates of $67.1 \%$ and $62.4 \%$, respectively. The perforation rate was $3.3-14.0 \%$, and the delayed perforation rate was $0.4-$ $0.7 \%$. Additionally, postoperative bleeding occurred in 1.5$2.1 \%$ of cases [12].

The high rate of perforation is due to the thinness of the colorectal wall compared to the gastric wall. A few clinical studies have focused on the risk factors that predict perforation during ESD for colorectal tumors. Large lesions, fibrosis, colonic location (due to a thinner wall than in the rectum), and less experience performing ESDs might be risk factors for perforation during $\operatorname{ESD}[2,7,33,34]$.

Closure of mucosal defects created during ESD is not routinely practiced in Japan, although some experts believe that such closure may decrease the risk of delayed bleeding and possibly perforation. At present, closure of the typically large ESD mucosal defect is impractical and technically challenging with currently available devices (e.g., hemoclips). The rate of perforation is higher than the rate of postoperative bleeding, but methods for preventing severe complications remain to be established for the management of postcolorectal ESD. Prophylactic closure with hemoclips may be effective in preventing the postoperative bleeding related to the endoscopic mucosal resection (EMR) of large $(\geq 2 \mathrm{~cm})$ sessile or flat colorectal lesions. In a cohort of polyps for which all polypectomies were performed using pure low-power coagulation current, the risk of delayed postpolypectomy hemorrhage decreased from $9.7 \%$ to $1.8 \%$ when comparing polypectomy sites that were not clipped with those that were completely clipped closed [35]. However, prophylactic clip closure has no benefit for the prevention of complications (postpolypectomy syndrome and perforation) other than delayed hemorrhage. We have reported that the prophylactic closure of large mucosal defects after colorectal ESD reduces the inflammatory reaction and relieves patient symptoms after colorectal ESD [36] (Figure 1). However, we could not obtain sufficient evidence to determine whether the prophylactic closure prevented delayed perforation and postoperative bleeding because of the small sample size and retrospective nature of the study. Future studies will require a larger sample size and a prospective study design.

At the completion of the resection, the artificial ulcer is carefully inspected for any visible vessels. These are typically coagulated using the coag grasper to prevent delayed bleeding. This is particularly important and may explain the observation that ESD has a generally lower rate of delayed bleeding compared with EMR [9].

2.2. Various Knives and Colorectal ESD. A large number of devices for ESD are now available in Japan [7, 13-31] (Table 1). These devices are divided into two broad categories: 


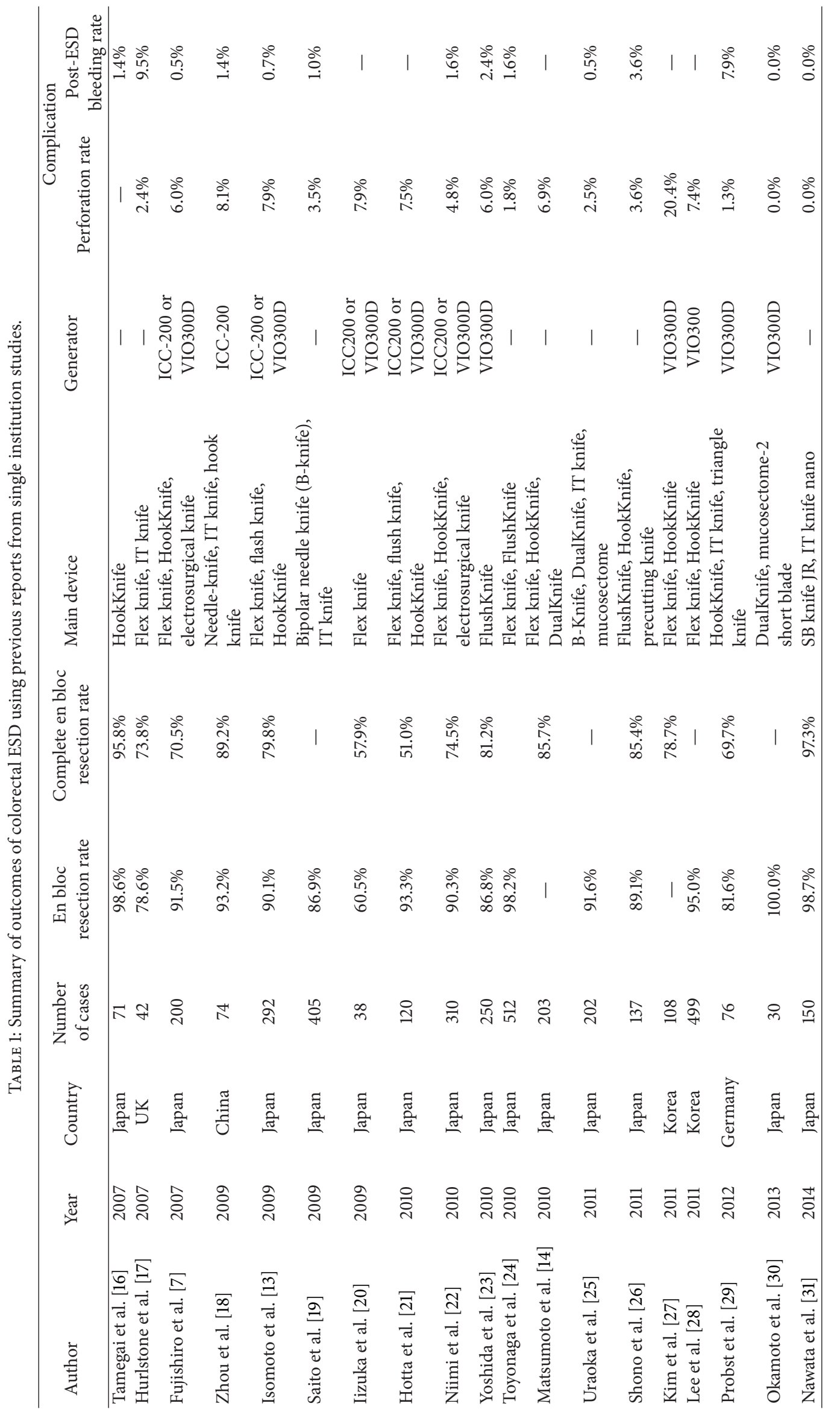




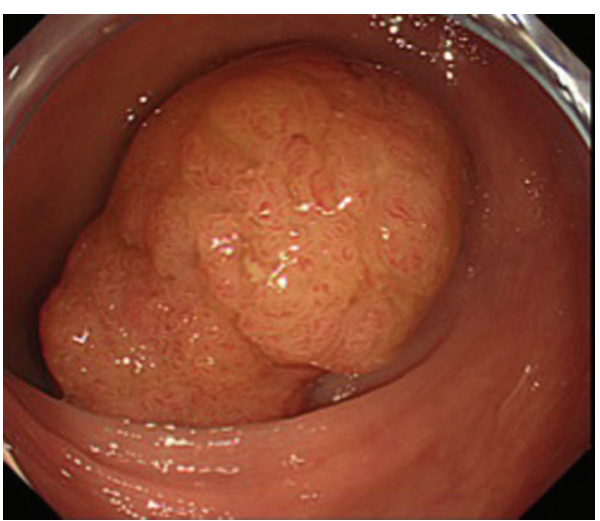

(a)

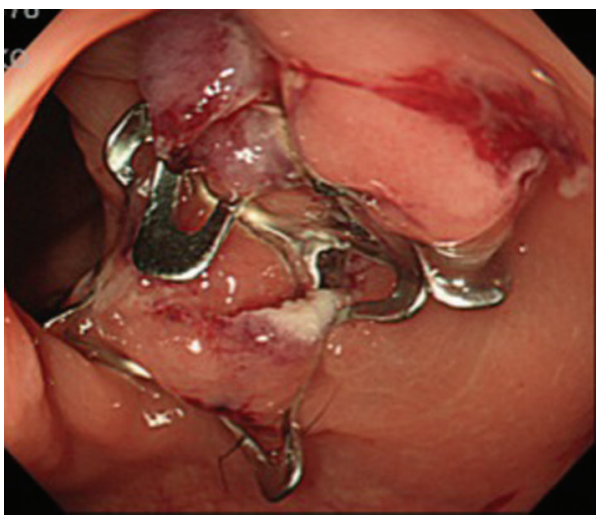

(c)

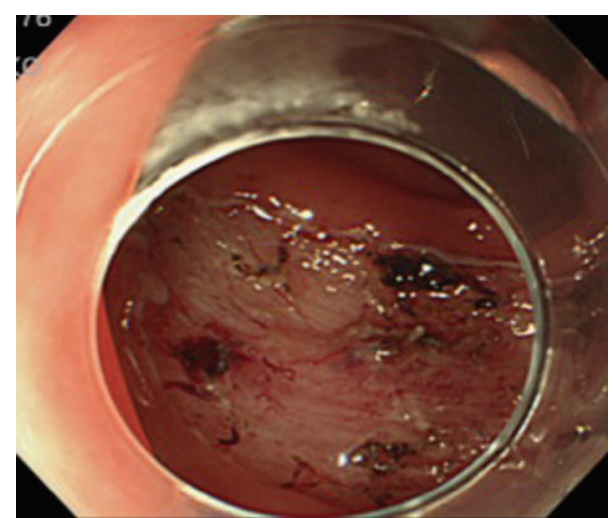

(b)

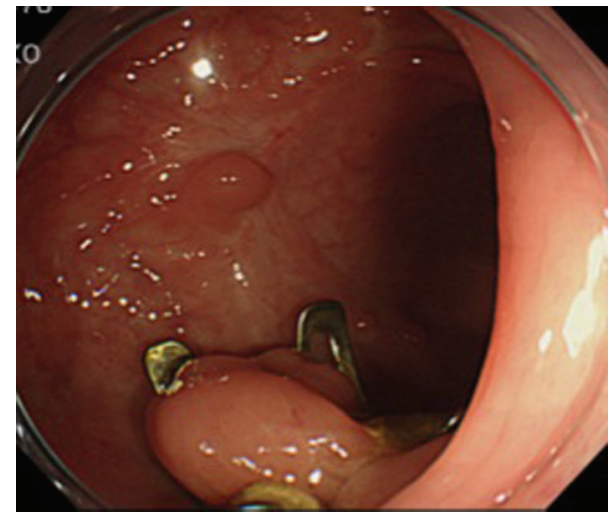

(d)

FIGURE 1: Endoscopic closure of an artificial ulcer with conventional clips and an OTSC system. (a) A large tumor, measuring 55 mm in diameter, located in the upper rectum. (b) A large mucosal defect after colorectal ESD. (c) Complete closure was performed using an OTSC system. (d) The endoscopic view at postoperative day 333.

the needle-knife type and the grasping (scissors) type. The needle-knife type can be further subdivided into the uncovered and covered (insulated) types. Among the obtuse, shorttipped types are the FlushKnife (Fujifilm Medical, Tokyo, Japan), the DualKnife (Olympus Medical Systems Co., Tokyo, Japan), the B-Knife (Zeon Medical, Tokyo, Japan), and the Splashneedle (Pentax Co., Tokyo, Japan) [33, 37, 38]. The FlushKnife and the Splashneedle are capable of injecting substances into the submucosa. These devices eliminate the need to switch between the knife and the injection needle $[37,39]$. The DualKnife has a ball disk at the tip of the knife, allowing the user to hook the submucosa. The BKnife is the only bipolar knife; burning of the muscularis propria layer is reduced with this knife compared with other monopolar knives. For this reason, the B-Knife may produce fewer complications, particularly perforations. Adapting to another type of knife requires time and practice by the user.

The HookKnife (Olympus Medical Systems Co., Tokyo, Japan) is particularly useful when dissection of the submucosa is difficult due to poor elevation of the submucosa [40].

Obtuse short-tipped knives, such as the DualKnife and the FlushKnife, can easily cause perforation when used on the thin colon wall due to the presence of folds. By contrast, it is difficult to cause perforations while using the HookKnife because the submucosa can be hooked and separated from the muscularis propria and cut safely [41]. However, use of the HookKnife requires an assistant to rotate the direction of the knife for proper device efficacy.

The insulated-tipped (IT) knife 2 (Olympus Medical Systems Co., Tokyo, Japan), the efficacy of which has been reported to be satisfactory in ESD for gastric tumors, is used in certain institutions [1]. The long blade of the ITknife 2 enables rapid dissection, thereby shortening the operation time and enabling coagulation in small vessels. However, mastering the ITknife 2 is difficult because the angle of the ITknife 2 to the mucosa is critical. In addition, the long blade of the ITknife 2 may cause large perforations. In Japan, a new type of insulated-tipped knife (called the ITknife nano (Olympus Optical Co., Ltd, Tokyo, Japan)) is used; this knife is smaller than the ITknife 2 and was invented to improve the safety and speed of submucosal dissection in the colon. A grasping-type scissor forceps has also been reported as another novel knife [42].

The Clutch Cutter device (Fujifilm, Tokyo, Japan) and SB knife Jr (Sumitomo Bakelite) are the major types of graspingtype scissor forceps [31, 43].

Cutting methods that involve the use of grasping-type scissors forceps, without fixing the knife to the target, are 


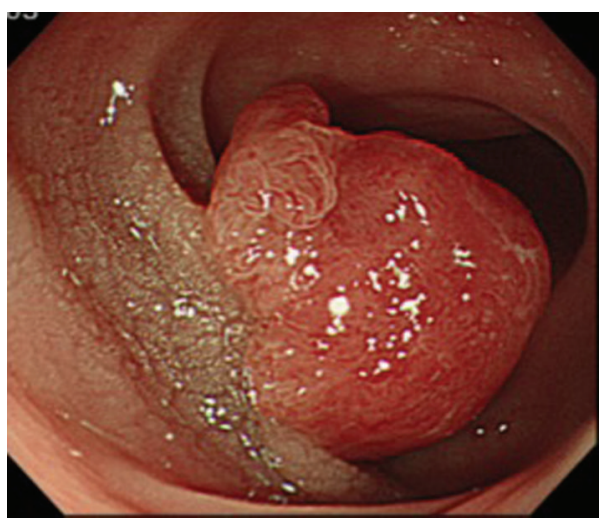

(a)

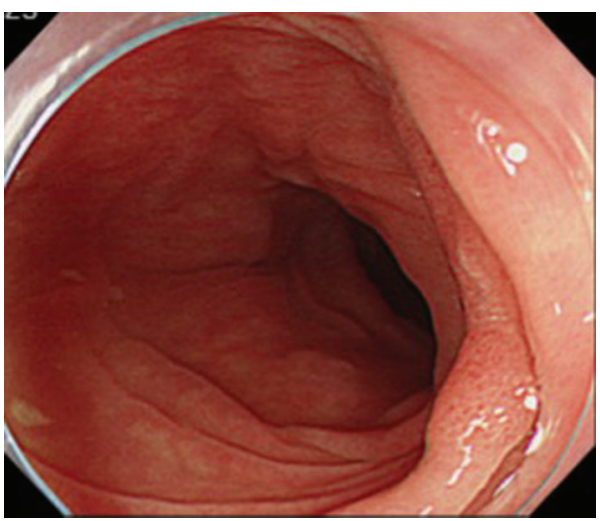

(c)

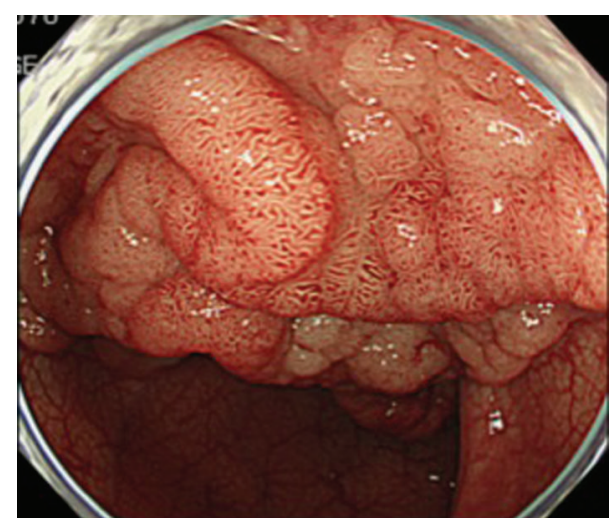

(b)

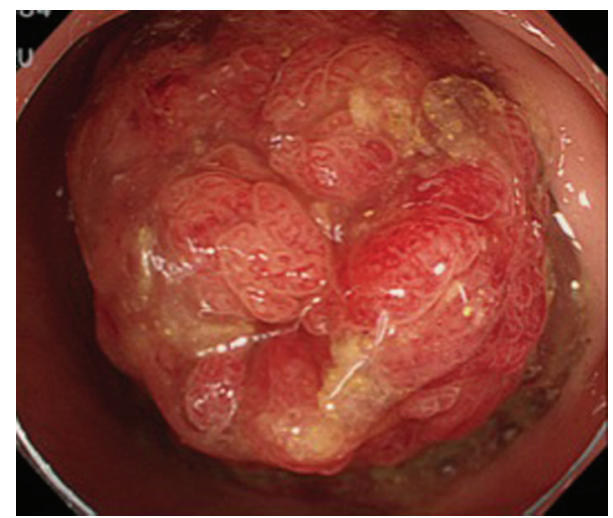

(d)

Figure 2: Difficult lesions with endoscopic treatment. (a) Deeper invasion of the submucosa in colorectal cancer. (b) A laterally spreading tumor occupying more than one-third of the bowel circumference or spanning more than two haustral folds. (c) Remnant lesion. (d) A large pedunculated polyp.

associated with a potential risk of major complications, such as perforation and bleeding, due to unexpected incision (i.e., because of cardiac or respiratory movement) [43]. In our institution, the DualKnife is primarily used, while the grasping scissors forceps is used when the risk of perforation is high due to the poor elevation of the submucosa and when facing the colon wall.

\section{EFTR in the Colon}

3.1. Indications for EFTR. The indications for EFTR include adenoma, intramucosal carcinomas, and slight submucosal invasion (<1000 micrometers below the muscularis mucosa; sm1) without lymphovascular infiltration, which are similar to the indications for ESD.

The risk of local recurrence is significantly higher in highrisk patients with submucosal rectal cancer than in patients with submucosal colon cancer who are treated with only endoscopic resection [44]. In these cases, hybrid NOTES or laparoscopic and endoscopic cooperative surgery might be recommended to perform lymphadenectomy. However, before resection of the tumor, we were unable to identify nodal involvement. Several reports have described the supplementation of ESD with sentinel node biopsy by NOTES $[45,46]$.
Additionally, the indications may include the following: (1) technically difficult ESD for early colorectal cancer (Figure 2) and (2) carcinoid tumors. These two aspects are considered to determine the need for EFTR for each lesion. Performing colorectal ESD is challenging in the presence of technically difficult lesions with severe fibrosis; recurrent lesions; lesions located at the bottom of the cecum, near the terminal ileum, and in the appendix; and large pedunculated polyps.

Isomoto et al. [13] reported that right-side colonic location and fibrosis were the most significant contributors to incomplete resection and that perforation was associated with large tumor size $(30 \mathrm{~mm})$ and the presence of fibrosis. They also reported that the risks of incomplete resection and perforation increased substantially when the contributive factors for each were combined. Matsumoto et al. reported that in cases of lesions with severe fibrosis, the rate of complete en bloc resection was low, and the perforation rate was high, even when ESD was performed by an experienced operator. However, clarification of the presence and extent of fibrosis before actual colorectal ESD is obviously impossible [14]. In contrast, Yoshida et al. reported that knife coagulation was the most common cause of perforation [47].

Choi et al. reported that in cases of a giant pedunculated polyp with (1) poor visualization of the stalk, (2) technical 
difficulties in snare positioning for en bloc resection, or (3) the need for trimming of the head, piecemeal snare polypectomy was not attempted, and endoscopic submucosal dissection was performed instead [48]. For large colonic polyps occupying more than one-third of the bowel circumference or spanning more than two haustral folds, combined endolaparoscopic resection is a viable treatment modality [4, $10,11]$. Recurrent lesions with fibrosis and large pedunculated polyps can be indications for EFTR, considering the longer operation time and the risk of complication, if they fulfill the criterion of no nodal metastasis.

Endoscopic treatment is considered to be curative for small carcinoid tumors $(<10 \mathrm{~mm})$ with an extremely low risk of metastasis [49]. Recently, ESD was reported to be an effective method for the treatment of rectal carcinoid tumors [50-52]. When the lesions are intermediate in size or massively invade the submucosal layer, which may result in tumor-positive margin resection, these can be indications for ESD or EFTR.

3.2. Procedural Methods. Schurr et al. [53] and Rajan et al. [54] reported the use of a full-thickness resection device (FTRD) consisting of a hollow, flexible shaft with a resection head and tissue manipulators. In a study by Schurr et al. [53], the FTRD was under development, and a conventional circular surgical stapler was used as a predicate device to imitate the procedure. Two studies reported in the same paper and an additional study published by Rajan et al. [54] were conducted using the FTRD with the goal of assessing the feasibility and safety of EFTR using this novel device. The tissue fold was excised, resulting in a stapled anastomosis. Use of the FTRD was focused on flat, elevated lesions with a diameter of up to $3 \mathrm{~cm}$ [53], including both adenomas and early colorectal carcinomas. Compared to TEM, the advantage of FTRD is that it can be used to target both rectal and colonic lesions up to the splenic flexure [53]. However, FTRD is disadvantageous for lesions involving flexures and curves because it requires straightening of the colon.

Raju et al. [55] reported on circular, full-thickness resection of the colon at approximately $20 \mathrm{~cm}$ from the anus (peritoneal portion of the colon) with a band-ligation device. They performed closure by using a median of 7 clips (range, 6-13 clips) and produced a median length of the closed defect on the serosal side of $3 \mathrm{~cm}$ (range, $1.5-4 \mathrm{~cm}$ ).

Von Rentlen et al. [56, 57] and Rieder et al. [58] described several variations of a grasp-and-snare technique. Von Renteln et al. [56] performed both pre- and postresection closure using an OTSC (Ovesco Endoscopy, Tubingen, Germany). A tissue anchor (Ovesco, Endoscopy) was inserted through a double-channel gastroscope (2T160, Olympus, Hamburg, Germany) to grasp the bowel wall and create a pseudopolyp. The base of the pseudopolyp was ligated with an Endoloop (HX-400U-30, Olympus) before snare resection.

A disadvantage of the grasp-and-snare technique is that it makes it difficult to produce a specimen with an adequate horizontal clearance margin. Rieder et al. [58] described a preresection closure method with laparoscopic overview using an OTSC mounted on a dual-channel gastroscope (GIF-2T-160, Olympus). Kennedy et al. [59] described a laparoendoscopic procedure using two endoscopes (R-scope, Olympus Keymed, and GIF-Q240, Olympus Keymed). Circumferential APC marks were placed at $1 \mathrm{~cm}$ from the edge of a simulated polyp created by the submucosal injection of ink. Prototype BraceBars (Olympus Medical Systems, Olympus), which are similar to the TAS system, were placed laparoscopically to invert the area bearing the polyp. Three pairs of BraceBars placed $1 \mathrm{~cm}$ from the endoluminal APC marks were required to invert the area, and the inversion site was oversewn laparoscopically. The created endoluminal fold was retracted with one endoscope (GIF-Q240, Olympus Keymed), and excision was performed using an endoscopic knife inserted through a working endoscope (R-scope, Olympus Keymed). Recently, Picasso et al. reported resection of flat, elevated polyps $(20 \mathrm{~mm})$ using EMR and full-thickness closure with an OTSC device in humans [60].

EFTR procedural methods are summarized in Table 2. These methods (1) mostly involve the use of a dual-channel scope, (2) require a laparoscopic assist, (3) are mainly used to resect the inner wall of the main lesion with a snare, and (4) produce better results for a small defect of the colorectal wall than with a large defect because of the need to close the mucosal defect completely.

The advantage of these methods is the ability to easily and quickly resect the main lesion and quickly close the colon wall defect. These methods are also favorable for preventing peritoneal infection and the dissemination of cancer cells to the peritoneal cavity. However, a dual-channel scope cannot easily turn around in a small circle compared to single-channel scopes. Thus, performing a complicated endoscopic treatment using a dual-channel scope may be difficult. The larger size of flat, elevated lesions (e.g., lateral spreading tumors) is difficult to resect when using only a snare. Endoscopic treatment for larger-sized lesions requires additional devices to support closure and suturing.

\subsection{The Potential for and Limitations of EFTR Using ESD} Devices. Recently, endoscopic resection of gastric intestinal stromal tumors (GISTs) or submucosal tumors has been performed with the use of ESD techniques and laparoscopicassisted suturing, or so-called laparoscopic and endoscopic cooperative surgery (LECS) [61] and hybrid NOTES [62]. When a large defect is created in the colon, it is difficult to maintain clear vision using the endoscopic platform for resection on the colon wall because of the air leaking out into the peritoneal cavity. To address the problem of air leaking out and collapsing the colon wall, we attempted EFTR with laparoscopic assistance for GISTs by using the equally spaced perforation technique, which prevents air from leaking out into the peritoneal cavity [62].

The equally spaced perforation technique is a resection method for easily achieving EFTR in which $1.5 \mathrm{~mm}$ perforation holes are created at $10 \mathrm{~mm}$ intervals and used as landmarks to perform EFTR. The mucosa was first cut circumferentially, and the submucosal layer was then cut (Figure 3(a)). Next, we created a small hole in the muscular layer using a needle-type knife (Figure 3(b)). Equidistant small dots enabled the correct resection of the muscular layer 


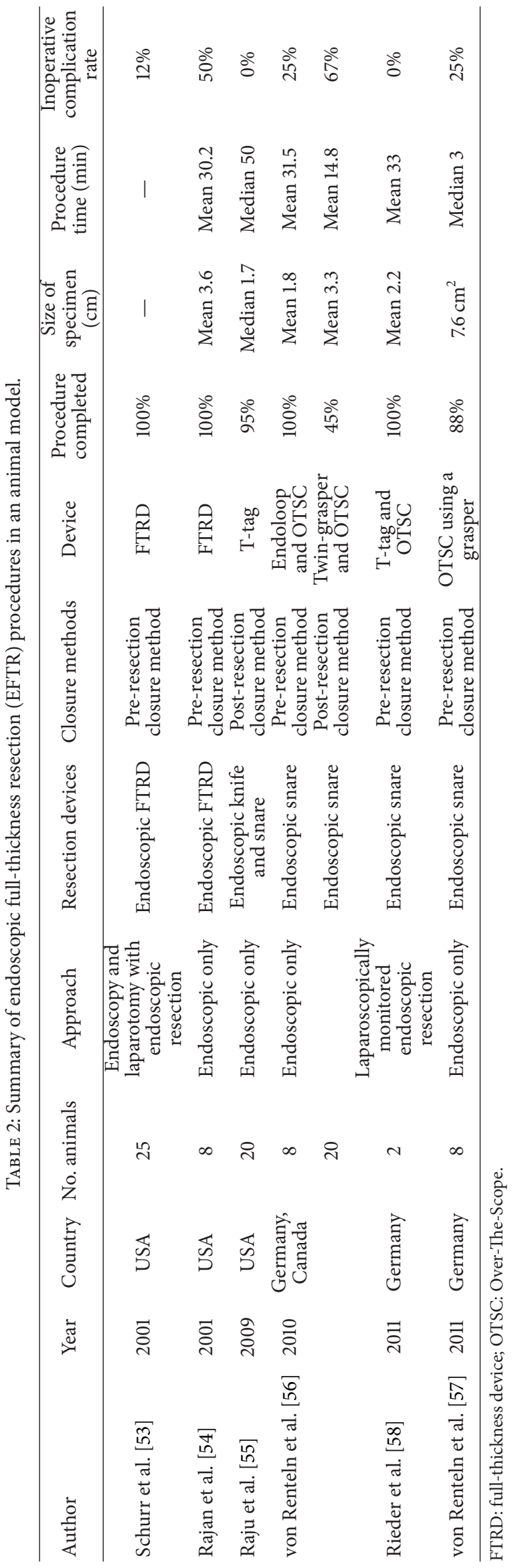




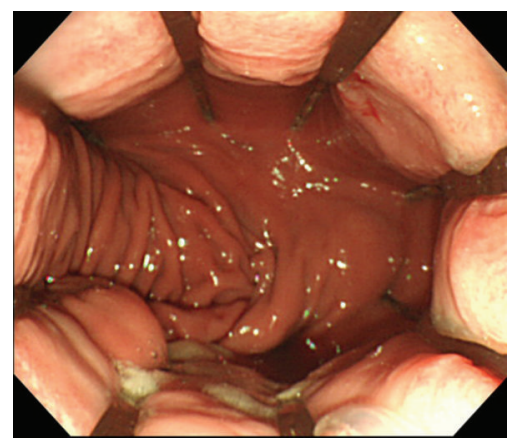

(a)

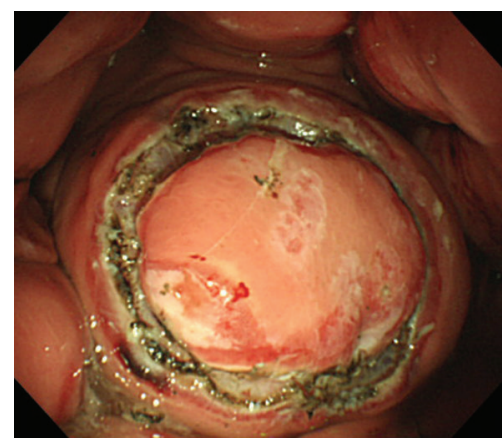

(b)

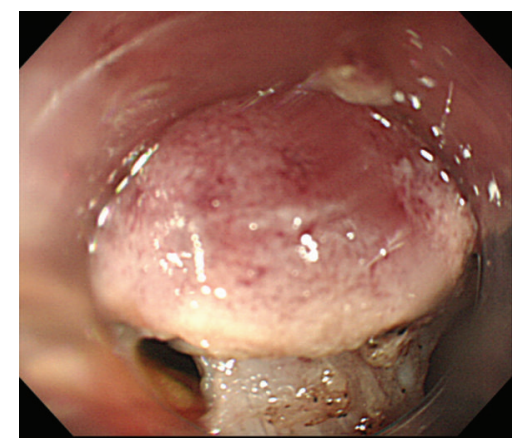

(c)

FIGURE 3: EFTR using ESD devices. (a) The mucosa was cut circumferentially, and the submucosal layer was then cut. (b) Next, we created a small hole in the muscular layer using a needle-type knife. (c) Equidistant small dots enabled the correct resection of the muscular layer using the ITknife.

using the ITknife (Figure 3(c)). Massive and spurting bleeding occasionally occurred during dissection of the muscular layer. Hiki recommends that the ESD procedure be used for submucosal, but not seromuscular, dissection because of poor bleeding control during treatment of the muscular layer [61]. For that reason, laparoscopic overview and assistance during EFTR improve the safety of the procedure by creating traction and laparoscopic hemostasis.

Several EFTR procedures have been described, and several problems existed when EFTR was performed using an ESD device. Postmortem findings from animal survival studies suggest a risk of peritoneal contamination and infection. Additionally, postresection closure risks the seeding of malignant cells into the peritoneal cavity in the case of early colorectal cancer.

\section{Endoscopic Suturing Devices}

4.1. OTSC. An OTSC (Ovesco, Tübingen, Germany) has been developed for the closure of small mural defects and bleeding ulcers [63]. Several case series have demonstrated the successful use of the OTSC in the closure of acute GI perforations, anastomotic leaks, bleeding lesions, and chronic GI fistulae [63-71].

Kirschniak et al. [63] initially described the use of this device in the successful closure of 2 small ( 4 and $8 \mathrm{~mm}$ ) iatrogenic colonic perforations and 2 deep mucosal resection sites (also 4 and $8 \mathrm{~mm}$ in size) in the colonic and gastric walls. The advantage of the OTSC is that it can easily and rapidly completely close a mural defect compared to other devices.

We evaluated the efficacy and safety of the OTSC in OTSC placement for 23 patients with GI bleeds, perforations, GI fistulae, and post-ESD artificial ulcers. The overall success rate was $82.6 \%$. A large lesion size (greater than $20 \mathrm{~mm}$ ) and delayed diagnosis were the major contributing factors to unsuccessful cases [71]. OTSCs may have limited efficacy in the following situations: (1) larger mural defects, (2) chronic inflammation, and (3) repeated attempts at closure.

Von Rentlen et al. [56, 57] described ligation of the base of a pseudopolyp with an Endoloop (HX-400U-30, Olympus) and an OTSC loaded onto a cap at the end of the endoscope; the OTSC was applied at the base of the Endoloop before snare resection. Earlier studies evaluating OTSCs for the closure of defects were only performed for defects up to $18 \mathrm{~mm}$ in size $[72,73]$.

These $18 \mathrm{~mm}$ openings were created using balloon dilatation, facilitating tissue approximation compared to EFTR defects. Outcomes studies have demonstrated that EFTR defects up to $2.7 \mathrm{~cm}$ can be adequately closed using OTSCs in the majority of cases. For defects larger than $2.7 \mathrm{~cm}$, OTSCs are not sufficient. For some colonic defects $>2.7 \mathrm{~cm}$, serial OTSC placement can be used with success, but closure may be associated with luminal obstruction depending on the location and configuration of the initial resection. Furthermore, large EFTR defects induce a distinct luminal collapse, rendering endoscopic closure very difficult [57].

We previously reported successful use of the OTSC in GI bleeds, perforations, and fistulae. In our experience, large lesion size (greater than $20 \mathrm{~cm}$ ) and delayed perforation were the major contributing factors in unsuccessful cases [71].

A potential indication for the removal of an OTSC could be its misplacement.

In our experience, it is difficult to deploy a second clip next to the first one. Several methods for removing OTSCs have been reported [74-76]. Removal of the first clip enables correct deployment of the second clip [77]. Arezzo et al. reported an interesting new technique involving the use of cold saline solution for the gentle removal of the OTSC [75]. Baron et al. described the use of argon plasma coagulation at high power; the optimal site for cutting the device appears to be at the hinge [76]. More recently, Fähndrich et al. described the use of an yttrium aluminum garnet laser to destroy and remove an OTSC in vivo [78].

However, regardless of the method used, the destroyed OTSC should be retrieved through an overtube to avoid tissue damage while retracting the OTSC through the gastroesophageal junction. Bar Suturing System. The Overstitch Endoscopic Suturing 


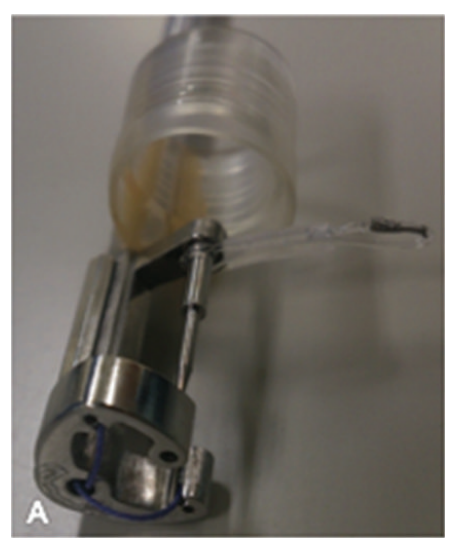

(a)

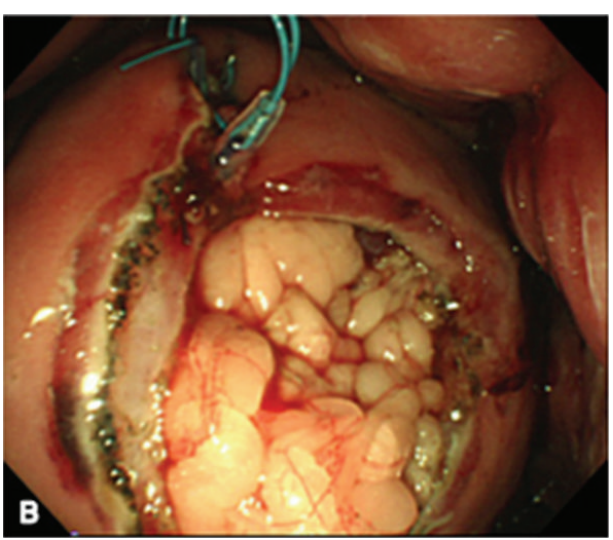

(b)

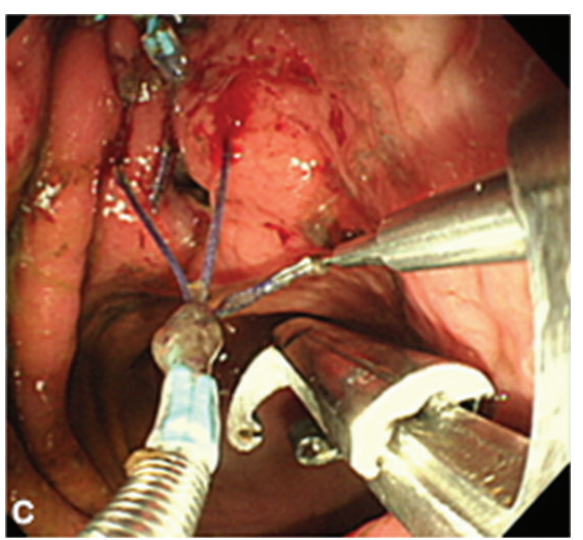

(c)

Figure 4: (a) Double-armed bar suturing system (DBSS). (b) Endoscopic view by using mechanical counter traction device. (c) Endoscopic suturing in animal experimental model.

System (Apollo Endosurgery, Austin, Tex) is a disposable, single-use suturing device that is mounted onto a doublechannel therapeutic endoscope and allows for the placement of either running or interrupted full-thickness sutures. The device represents an evolution of the previously described Eagle Claw device $[79,80]$.

This suturing device has been used successfully for the closure of persistent gastrocutaneous fistulae [81-86], fixation of esophageal stents, suturing of ulcers, and other indications. Kantsevoy et al. reported that closure of a large post-ESD mucosal defect in the colon using the Overstitch Endoscopic Suturing Device decreased treatment cost by eliminating the need for hospitalization.

Recently, we were challenged to perform an EFTR using the ESD method and to suture a large mucosal defect using a new suturing system and mechanical counter traction device in animal models [87-89] (Figure 4). For the suturing of resection wounds $>40 \mathrm{~mm}$ in the stomach, these devices enabled the complete suture of a large mural defect. We aim to improve these devices so that large mural defects can be sutured more simply and quickly.

\section{Conclusions}

ESD has been established as a minimally invasive endoscopic treatment for tumors of the digestive tract wall and yields high en bloc resection rates for larger tumors of the esophagus, stomach, and colon. The establishment of EFTR and endoscopic suturing may cause the following problems: the dissemination of malignant cells, infection, hemostasis, and anastomotic leakage. Laparoscopic overview and assistance during EFTR improve the safety of the procedure by creating traction and laparoscopic hemostasis. Additionally, combining endoscopy and laparoscopy is important when endoscopic treatment alone is inadequate for disease control. Furthermore, innovative methods and new devices for EFTR and suturing will enable the local resection of tumors via minimally invasive surgery.
Innovative methods and new devices for EFTR and suturing are evolving and may change traditional paradigms to achieve minimally invasive surgery for colorectal cancer.

\section{Conflict of Interests}

The authors declare that there is no conflict of interests.

\section{Acknowledgments}

The authors thank Dr. Makoto Oryu and Kazi Rafiq for providing technical and editorial assistance.

\section{References}

[1] Y. Saito, M. Fukuzawa, T. Matsuda et al., "Clinical outcome of endoscopic submucosal dissection versus endoscopic mucosal resection of large colorectal tumors as determined by curative resection," Surgical Endoscopy, vol. 24, no. 2, pp. 343-352, 2010.

[2] Y. Saito, T. Uraoka, Y. Yamaguchi et al., "A prospective, multicenter study of 1111 colorectal endoscopic submucosal dissections (with video)," Gastrointestinal Endoscopy, vol. 72, no. 6, pp. 1217-1225, 2010.

[3] Y. Kopelman, P. D. Siersema, A. Bapaye, and D. Kopelman, "Endoscopic full-thickness GI wall resection: current status," Gastrointestinal Endoscopy, vol. 75, no. 1, pp. 165-173, 2012.

[4] S. Tanaka, S. Oka, I. Kaneko et al., "Endoscopic submucosal dissection for colorectal neoplasia: possibility of standardization," Gastrointestinal Endoscopy, vol. 66, no. 1, pp. 100-107, 2007.

[5] S. Tanaka, Y. Tamegai, S. Tsuda, Y. Saito, N. Yahagi, and H.O. Yamano, "Multicenter questionnaire survey on the current situation of colorectal endoscopic submucosal dissection in Japan," Digestive Endoscopy, vol. 22, supplement s1, pp. S2-S8, 2010.

[6] N. Yahagi, M. Fujishiro, and M. Omata, "Endoscopic submucosal dissection of colorectal lesion," Digestive Endoscopy, vol. 16, supplement s2, pp. S178-S181, 2004.

[7] M. Fujishiro, N. Yahagi, N. Kakushima et al., "Outcomes of endoscopic submucosal dissection for colorectal epithelial 
neoplasms in 200 consecutive cases," Clinical Gastroenterology and Hepatology, vol. 5, no. 6, pp. 678-683, 2007.

[8] T. Uraoka, Y. Kawahara, J. Kato, Y. Saito, and K. Yamamoto, "Endoscopic submucosal dissection in the colorectum: present status and future prospects," Digestive Endoscopy, vol. 21, supplement s1, pp. S13-S16, 2009.

[9] N. Kobayashi, Y. Saito, T. Uraoka, T. Matsuda, H. Suzuki, and T. Fujii, "Treatment strategy for laterally spreading tumors in Japan: before and after the introduction of endoscopic submucosal dissection," Journal of Gastroenterology and Hepatology, vol. 24, no. 8, pp. 1387-1392, 2009.

[10] Y. Saito, H. Kawano, Y. Takeuchi et al., "Current status of colorectal endoscopic submucosal dissection in Japan and other Asian countries: progressing towards technical standardization," Digestive Endoscopy, vol. 24, supplement s1, pp. 67-72, 2012.

[11] S. Tanaka, S. Oka, and K. Chayama, "Colorectal endoscopic submucosal dissection: present status and future perspective, including its differentiation from endoscopic mucosal resection," Journal of Gastroenterology, vol. 43, no. 9, pp. 641-651, 2008.

[12] S. Tanaka, M. Terasaki, N. Hayashi, S. Oka, and K. Chayama, "Warning for unprincipled colorectal endoscopic submucosal dissection: accurate diagnosis and reasonable treatment strategy," Digestive Endoscopy, vol. 25, no. 2, pp. 107-116, 2013.

[13] H. Isomoto, H. Nishiyama, N. Yamaguchi et al., "Clinicopathological factors associated with clinical outcomes of endoscopic submucosal dissection for colorectal epithelial neoplasms," Endoscopy, vol. 41, no. 8, pp. 679-683, 2009.

[14] A. Matsumoto, S. Tanaka, S. Oba et al., "Outcome of endoscopic submucosal dissection for colorectal tumors accompanied by fibrosis," Scandinavian Journal of Gastroenterology, vol. 45, no. 11, pp. 1329-1337, 2010.

[15] N. Matsui, K. Akahoshi, K. Nakamura, E. Ihara, and H. Kita, "Endoscopic submucosal dissection for removal of superficial gastrointestinal neoplasms: a technical review," World Journal of Gastrointestinal Endoscopy, vol. 4, no. 4, pp. 123-136, 2012.

[16] Y. Tamegai, Y. Saito, N. Masaki et al., "Endoscopic submucosal dissection: a safe technique for colorectal tumors," Endoscopy, vol. 39, no. 5, pp. 418-422, 2007.

[17] D. P. Hurlstone, R. Atkinson, D. S. Sanders, M. Thomson, S. S. Cross, and S. Brown, "Achieving R0 resection in the colorectum using endoscopic submucosal dissection," British Journal of Surgery, vol. 94, no. 12, pp. 1536-1542, 2007.

[18] P.-H. Zhou, L.-Q. Yao, and X.-Y. Qin, "Endoscopic submucosal dissection for colorectal epithelial neoplasm," Surgical Endoscopy, vol. 23, no. 7, pp. 1546-1551, 2009.

[19] Y. Saito, T. Sakamoto, S. Fukunaga, T. Nakajima, S. Kuriyama, and T. Matsuda, "Endoscopic submucosal dissection (ESD) for colorectal tumors," Digestive Endoscopy, vol. 21, supplement s1, pp. S7-S12, 2009.

[20] H. Iizuka, S. Okamura, Y. Onozato, H. Ishihara, S. Kakizaki, and M. Mori, "Endoscopic submucosal dissection for colorectal tumors," Gastroenterologie Clinique et Biologique, vol. 33, no. 1011, pp. 1004-1011, 2009.

[21] K. Hotta, T. Oyama, T. Shinohara et al., "Learning curve for endoscopic submucosal dissection of large colorectal tumors," Digestive Endoscopy, vol. 22, no. 4, pp. 302-306, 2010.

[22] K. Niimi, M. Fujishiro, S. Kodashima et al., "Long-term outcomes of endoscopic submucosal dissection for colorectal epithelial neoplasms," Endoscopy, vol. 42, no. 9, pp. 723-729, 2010.
[23] N. Yoshida, Y. Naito, M. Kugai et al., "Efficient hemostatic method for endoscopic submucosal dissection of colorectal tumors," World Journal of Gastroenterology, vol. 16, no. 33, pp. 4180-4186, 2010.

[24] T. Toyonaga, M. Man-i, R. Chinzei et al., "Endoscopic treatment for early stage colorectal tumors: the comparison between EMR with small incision, simplified ESD, and ESD using the standard flush knife and the ball tipped flush knife," Acta Chirurgica Ingoslavica, vol. 57, no. 3, pp. 41-46, 2010.

[25] T. Uraoka, R. Higashi, J. Kato et al., "Colorectal endoscopic submucosal dissection for elderly patients at least 80 years of age," Surgical Endoscopy, vol. 25, no. 9, pp. 3000-3007, 2011.

[26] T. Shono, K. Ishikawa, Y. Ochiai et al., "Feasibility of endoscopic submucosal dissection: a new technique for en bloc resection of a large superficial tumor in the colon and rectum," International Journal of Surgical Oncology, vol. 2011, Article ID 948293, 6 pages, 2011.

[27] E. S. Kim, K. B. Cho, K. S. Park et al., "Factors predictive of perforation during endoscopic submucosal dissection for the treatment of colorectal tumors," Endoscopy, vol. 43, no. 7, pp. 573-578, 2011.

[28] E.-J. Lee, J. B. Lee, Y. S. Choi et al., "Clinical risk factors for perforation during endoscopic submucosal dissection (ESD) for large-sized, nonpedunculated colorectal tumors," Surgical Endoscopy, vol. 26, no. 6, pp. 1587-1594, 2011.

[29] A. Probst, D. Golger, M. Anthuber, B. Märkl, and H. Messmann, "Endoscopic submucosal dissection in large sessile lesions of the rectosigmoid: learning curve in a European center," Endoscopy, vol. 44, no. 7, pp. 660-667, 2012.

[30] K. Okamoto, S. Kitamura, N. Muguruma et al., "Mucosectom2short blade for safe and efficient endoscopic submucosal dissection of colorectal tumors," Endoscopy, vol. 45, no. 11, pp. 928930, 2013.

[31] Y. Nawata, K. Homma, and Y. Suzuki, "Retrospective study of technical aspects and complications of endoscopic submucosal dissection for large superficial colorectal tumors," Digestive Endoscopy, 2014.

[32] S. Farhat, S. Chaussade, T. Ponchon et al., "Endoscopic submucosal dissection in a European setting. A multi-institutional report of a technique in development," Endoscopy, vol. 43, no. 8, pp. 664-670, 2011.

[33] Y. Saito, T. Uraoka, T. Matsuda et al., "Endoscopic treatment of large superficial colorectal tumors: a case series of 200 endoscopic submucosal dissections (with video)," Gastrointestinal Endoscopy, vol. 66, no. 5, pp. 966-973, 2007.

[34] G. Jeong, J. H. Lee, M. K. Yu et al., "Non-surgical management of microperforation induced by EMR of the stomach," Digestive and Liver Disease, vol. 38, no. 8, pp. 605-608, 2006.

[35] H. Liaquat, E. Rohn, and D. K. Rex, "Prophylactic clip closure reduced the risk of delayed postpolypectomy hemorrhage: experience in 277 clipped large sessile or flat colorectal lesions and 247 control lesions," Gastrointestinal Endoscopy, vol. 77, no. 3, pp. 401-407, 2013.

[36] S. Fujihara, H. Mori, H. Kobara et al., "The efficacy and safety of prophylactic closure for a large mucosal defect after colorectal endoscopic submucosal dissection," Oncology Reports, vol. 30, no. 1, pp. 85-90, 2013.

[37] T. Toyonaga, M. Man-I, Y. Morita et al., "The new resources of treatment for early stage colorectal tumors: EMR with small incision and simplified endoscopic submucosal dissection," Digestive Endoscopy, vol. 21, supplement s1, pp. S31-S37, 2009. 
[38] M. Fujishiro, S. Kodashima, O. Goto et al., "Technical feasibility of endoscopic submucosal dissection of gastrointestinal epithelial neoplasms with a splash-needle," Surgical Laparoscopy, Endoscopy \& Percutaneous Techniques, vol. 18, no. 6, pp. 592$597,2008$.

[39] Y. Takeuchi, N. Uedo, R. Ishihara et al., "Efficacy of an endoknife with a water-jet function (Flushknife) for endoscopic submucosal dissection of superficial colorectal neoplasms," The American Journal of Gastroenterology, vol. 105, no. 2, pp. 314322, 2010.

[40] N. Yoshida, Y. Naito, K. Sakai et al., "Outcome of endoscopic submucosal dissection for colorectal tumors in elderly people," International Journal of Colorectal Disease, vol. 25, no. 4, pp. 455-461, 2010.

[41] N. Yoshida, N. Yagi, Y. Naito, and T. Yoshikawa, "Safe procedure in endoscopic submucosal dissection for colorectal tumors focused on preventing complications," World Journal of Gastroenterology, vol. 16, no. 14, pp. 1688-1695, 2010.

[42] K. Akahoshi, Y. Motomura, M. Kubokawa et al., "Endoscopic submucosal dissection of a rectal carcinoid tumor using grasping type scissors forceps," World Journal of Gastroenterology, vol. 15, no. 17, pp. 2162-2165, 2009.

[43] K. Akahoshi, H. Akahane, A. Murata, H. Akiba, and M. Oya, "Endoscopic submucosal dissection using a novel grasping type scissors forceps," Endoscopy, vol. 39, no. 12, pp. 1103-1105, 2007.

[44] H. Ikematsu, Y. Yoda, T. Matsuda et al., "Long-term outcomes after resection for submucosal invasive colorectal cancers," Gastroenterology, vol. 144, no. 3, pp. 551-559, e514, 2013.

[45] R. A. Cahill, S. Perretta, J. Leroy, B. Dallemagne, and J. Marescaux, "Lymphatic mapping and sentinel node biopsy in the colonic mesentery by natural orifice transluminal endoscopic surgery (NOTES)," Annals of Surgical Oncology, vol. 15, no. 10, pp. 2677-2683, 2008.

[46] R. A. Cahill, M. Asakuma, S. Perretta et al., "Supplementation of endoscopic submucosal dissection with sentinel node biopsy performed by natural orifice transluminal endoscopic surgery (NOTES) (with video)," Gastrointestinal Endoscopy, vol. 69, no. 6, pp. 1152-1160, 2009.

[47] N. Yoshida, N. Wakabayashi, K. Kanemasa et al., "Endoscopic submucosal dissection for colorectal tumors: technical difficulties and rate of perforation," Endoscopy, vol. 41, no. 9, pp. 758761, 2009.

[48] Y. S. Choi, J. B. Lee, E.-J. Lee et al., "Can endoscopic submucosal dissection technique be an alternative treatment option for a difficult giant $(\geq 30 \mathrm{~mm})$ pedunculated colorectal polyp?" Diseases of the Colon \& Rectum, vol. 56, no. 5, pp. 660-666, 2013.

[49] C. H. Park, J. H. Cheon, J. O. Kim et al., "Criteria for decision making after endoscopic resection of well-differentiated rectal carcinoids with regard to potential lymphatic spread," Endoscopy, vol. 43, no. 9, pp. 790-795, 2011.

[50] D. S. Lee, S. W. Jeon, S. Y. Park et al., "The feasibility of endoscopic submucosal dissection for rectal carcinoid tumors: comparison with endoscopic mucosal resection," Endoscopy, vol. 42, no. 8, pp. 647-651, 2010.

[51] H.-W. Park, J.-S. Byeon, Y. S. Park et al., "Endoscopic submucosal dissection for treatment of rectal carcinoid tumors," Gastrointestinal Endoscopy, vol. 72, no. 1, pp. 143-149, 2010.

[52] H. Kobara, H. Mori, K. Rafiq et al., "Indications of endoscopic submucosal dissection for symptomatic benign gastrointestinal subepithelial or carcinoid tumors originating in the submucosa," Molecular and Clinical Oncology, vol. 1, no. 6, pp. 10021008, 2013.
[53] M. O. Schurr, G. Buess, H. Raestrup et al., "Full thickness resection device (FTRD) for endoluminal removal of large bowel tumours: development of the instrument and related experimental studies," Minimally Invasive Therapy \& Allied Technologies, vol. 10, no. 6, pp. 301-309, 2001.

[54] E. Rajan, C. J. Gostout, L. J. Burgart et al., "First endoluminal system for transmural resection of colorectal tissue with a prototype full-thickness resection device in a porcine model," Gastrointestinal Endoscopy, vol. 55, no. 7, pp. 915-920, 2002.

[55] G. S. Raju, A. Malhotra, and I. Ahmed, "Colonoscopic fullthickness resection of the colon in a porcine model as a prelude to endoscopic surgery of difficult colon polyps: a novel technique (with videos)," Gastrointestinal Endoscopy, vol. 70, no. 1, pp. 159-165, 2009.

[56] D. von Renteln, A. Schmidt, M. C. Vassiliou, H.-U. Rudolph, and K. Caca, "Endoscopic full-thickness resection and defect closure in the colon," Gastrointestinal Endoscopy, vol. 71, no. 7, pp. 1267-1273, 2010.

[57] D. von Renteln, T. Kratt, T. Rösch, U. W. Denzer, and G. Schachschal, "Endoscopic full-thickness resection in the colon by using a clip-and-cut technique: an animal study," Gastrointestinal Endoscopy, vol. 74, no. 5, pp. 1108-1114, 2011.

[58] E. Rieder, D. V. Martinec, C. M. Dunst, and L. L. Swanström, "A novel technique for natural orifice endoscopic full-thickness colon wall resection: an experimental pilot study," Journal of the American College of Surgeons, vol. 213, no. 3, pp. 422-429, 2011.

[59] R. H. Kennedy, R. A. Cahill, P. Sibbons, and C. Fraser, "The "FLEX" procedure: a new technique for full-thickness laparoendoscopic excision in the colon," Endoscopy, vol. 43, no. 3, pp. 223-229, 2011.

[60] M. Picasso, A. Parodi, D. A. Fisher, S. Blanchi, and M. Conio, "Full thickness endoscopic resection of a colonic cancer: a case report," Clinics and Research in Hepatology and Gastroenterology, vol. 37, no. 4, pp. e99-e101, 2013.

[61] N. Hiki, Y. Yamamoto, T. Fukunaga et al., "Laparoscopic and endoscopic cooperative surgery for gastrointestinal stromal tumor dissection," Surgical Endoscopy, vol. 22, no. 7, pp. 1729$1735,2008$.

[62] H. Mori, H. Kobara, M. Kobayashi et al., "Establishment of pure NOTES procedure using a conventional flexible endoscope: review of six cases of gastric gastrointestinal stromal tumors," Endoscopy, vol. 43, no. 7, pp. 631-634, 2011.

[63] A. Kirschniak, T. Kratt, D. Stüker, A. Braun, M.-O. Schurr, and A. Königsrainer, "A new endoscopic over-the-scope clip system for treatment of lesions and bleeding in the GI tract: first clinical experiences," Gastrointestinal Endoscopy, vol. 66, no. 1, pp. 162167, 2007.

[64] D. von Renteln, U. W. Denzer, G. Schachschal, M. Anders, S. Groth, and T. Rösch, "Endoscopic closure of GI fistulae by using an over-the-scope clip (with videos)," Gastrointestinal Endoscopy, vol. 72, no. 6, pp. 1289-1296, 2010.

[65] A. Repici, A. Arezzo, G. de Caro et al., "Clinical experience with a new endoscopic over-the-scope clip system for use in the GI tract," Digestive and Liver Disease, vol. 41, no. 6, pp. 406-410, 2009.

[66] F. Iacopini, N. di Lorenzo, F. Altorio, M.-O. Schurr, and A. Scozzarro, "Over-the-scope clip closure of two chronic fistulas after gastric band penetration," World Journal of Gastroenterology, vol. 16, no. 13, pp. 1665-1669, 2010. 
[67] A. Parodi, A. Repici, A. Pedroni, S. Blanchi, and M. Conio, "Endoscopic management of GI perforations with a new overthe-scope clip device (with videos)," Gastrointestinal Endoscopy, vol. 72, no. 4, pp. 881-886, 2010.

[68] J. Pohl, M. Borgulya, D. Lorenz, and C. Ell, "Endoscopic closure of postoperative esophageal leaks with a novel over-the-scope clip system," Endoscopy, vol. 42, no. 9, pp. 757-759, 2010.

[69] A. Kirschniak, N. Subotova, D. Zieker, A. Königsrainer, and T. Kratt, "The Over-The-Scope Clip (OTSC) for the treatment of gastrointestinal bleeding, perforations, and fistulas," Surgical Endoscopy, vol. 25, no. 9, pp. 2901-2905, 2011.

[70] L. Seebach, P. Bauerfeind, and C. Gubler, "'Sparing the surgeon": clinical experience with over-the-scope clips for gastrointestinal perforation," Endoscopy, vol. 42, no. 12, pp. 1108-1111, 2010.

[71] N. Nishiyama, H. Mori, H. Kobara et al., "Efficacy and safety of over-the-scope clip: including complications after endoscopic submucosal dissection," World Journal of Gastroenterology, vol. 19, no. 18, pp. 2752-2760, 2013.

[72] D. von Renteln, A. Schmidt, M. C. Vassiliou, M. Gieselmann, and K. Caca, "Natural orifice transluminal endoscopic surgery gastrotomy closure with an over-the-endoscope clip: a randomized, controlled porcine study (with videos)," Gastrointestinal Endoscopy, vol. 70, no. 4, pp. 732-739, 2009.

[73] D. von Renteln, A. Schmidt, M. C. Vassiliou, H.-U. Rudolph, M. Gieselmann, and K. Caca, "Endoscopic closure of large colonic perforations using an over-the-scope clip: a randomized controlled porcine study," Endoscopy, vol. 41, no. 6, pp. 481-486, 2009.

[74] H. Neumann, H. Diebel, K. Mönkemüller et al., "Description of a new, endoscopic technique to remove the over-the-scopeclip in an ex vivo porcine model (with video)," Gastrointestinal Endoscopy, vol. 76, no. 5, pp. 1009-1013, 2012.

[75] A. Arezzo, A. Bullano, H. Fischer, and M. Morino, "The way to remove an over-the-scope-clip (with video)," Gastrointestinal Endoscopy, vol. 77, no. 6, pp. 974-975, 2013.

[76] T. H. Baron, L. M. Song, A. Ross, J. L. Tokar, S. Irani, and R. A. Kozarek, "Use of an over-the-scope clipping device: multicenter retrospective results of the first U.S. experience (with videos)," Gastrointestinal Endoscopy, vol. 76, no. 1, pp. 202-208, 2012.

[77] K. Mönkemüller, J. Toshniwal, M. Zabielski, K. Vormbrock, and H. Neumann, "Utility of the " bear claw", or over-the-scope clip (OTSC) system, to provide endoscopic hemostasis for bleeding posterior duodenal ulcers," Endoscopy, vol. 44, supplement 2, pp. E412-E413, 2012.

[78] M. Fähndrich, M. Sandmann, and M. Heike, "Removal of over the scope clips (OTSC) with an Nd:YAG laser," Zeitschrift für Gastroenterologie, vol. 49, no. 5, pp. 579-583, 2011.

[79] P. W. Y. Chiu, B. Hu, J. Y. W. Lau, L. C. L. Sun, J. J. Y. Sung, and S. S. C. Chung, "Endoscopic plication of massively bleeding peptic ulcer by using the Eagle Claw VII device: a feasibility study in a porcine model," Gastrointestinal Endoscopy, vol. 63, no. 4, pp. 681-685, 2006.

[80] B. Hu, S. C. S. Chung, L. C. L. Sun et al., "Eagle Claw II: a novel endosuture device that uses a curved needle for major arterial bleeding: a bench study," Gastrointestinal Endoscopy, vol. 62, no. 2, pp. 266-270, 2005.

[81] S. V. Kantsevoy and P. J. Thuluvath, "Successful closure of a chronic refractory gastrocutaneous fistula with a new endoscopic suturing device (with video)," Gastrointestinal Endoscopy, vol. 75, no. 3, pp. 688-690, 2012.

[82] R. R. Watson, P. Jirapinyo, and C. C. Thompson, "Endoscopic repair of post- operative gastrointestinal fistulae using a novel endoscopic suturingdevice: technical feasibility and safety," Gastroenterology, vol. 140, no. 5, supplement 1, pp. S-118, 2011.

[83] S. V. Kantsevoy and M. Bitner, "Esophageal stent fixation with endoscopic suturing device (with video)," Gastrointestinal Endoscopy, vol. 76, no. 6, pp. 1251-1255, 2012.

[84] P. Jirapinyo, R. R. Watson, and C. C. Thompson, "Use of a novel endoscopic suturing device to treat recalcitrant marginal ulceration (with video)," Gastrointestinal Endoscopy, vol. 76, no. 2, pp. 435-439, 2012.

[85] E. Rieder, C. M. Dunst, D. V. Martinec, M. A. Cassera, and L. L. Swanstrom, "Endoscopic suture fixation of gastrointestinal stents: proof of biomechanical principles and early clinical experience," Endoscopy, vol. 44, no. 12, pp. 1121-1126, 2012.

[86] E. A. Bonin, L. M. W. K. Song, Z. S. Gostout, J. Bingener, and C. J. Gostout, "Closure of a persistent esophagopleural fistula assisted by a novel endoscopic suturing system," Endoscopy, vol. 44, supplement 2, pp. E8-E9, 2012.

[87] H. Mori, H. Kobara, S. Fujihara et al., "Feasibility of pure EFTR using an innovative new endoscopic suturing device: the Double-arm-bar Suturing System (with video)," Surgical Endoscopy, vol. 28, no. 2, pp. 683-690, 2014.

[88] H. Mori, H. Kobara, K. Rafiq et al., "New flexible endoscopic full-thickness suturing device: a triple-arm-bar suturing system," Endoscopy, vol. 45, no. 8, pp. 649-654, 2013.

[89] H. Mori, K. Rafiq, H. Kobara et al., "Innovative noninsufflation EFTR: sufficient endoscopic operative field by mechanical counter traction device," Surgical Endoscopy, vol. 27, no. 8, pp. 3028-3034, 2013. 


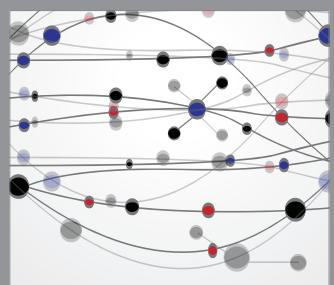

The Scientific World Journal
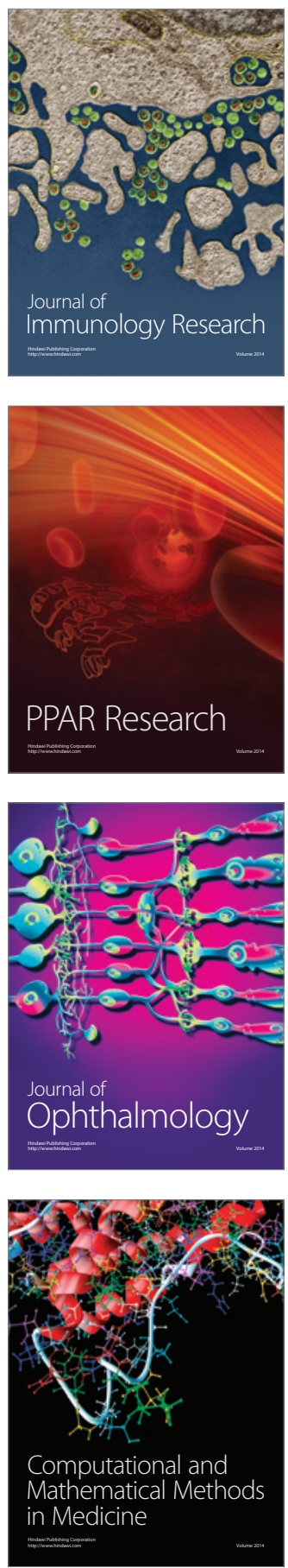

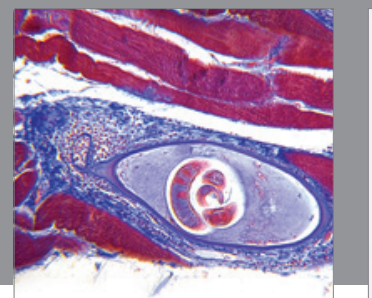

Gastroenterology

Research and Practice
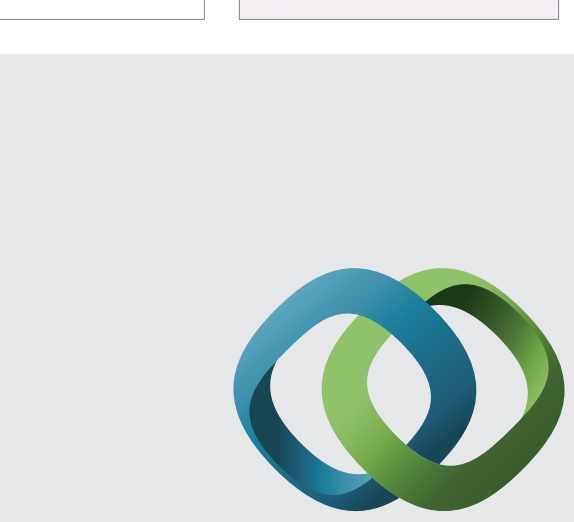

\section{Hindawi}

Submit your manuscripts at

http://www.hindawi.com
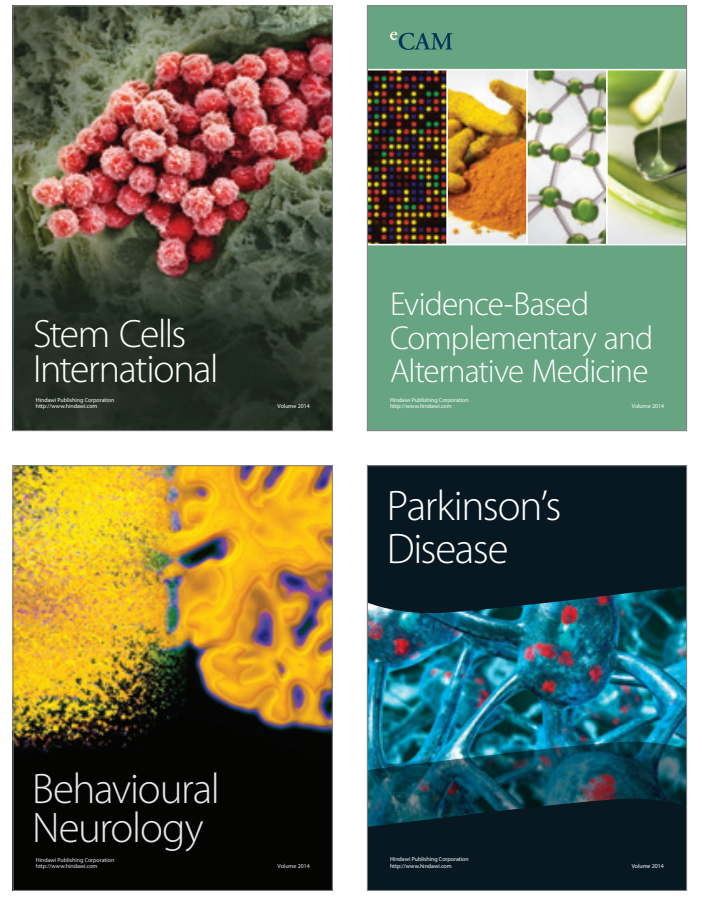
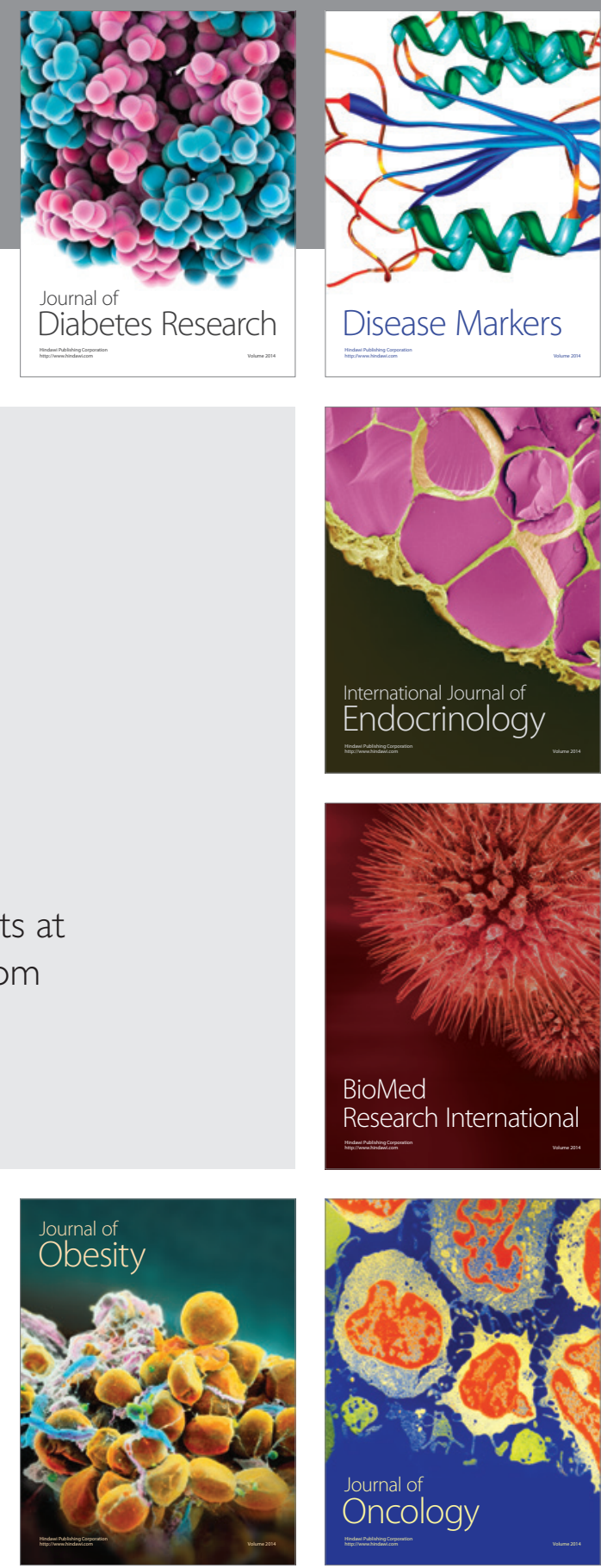

Disease Markers
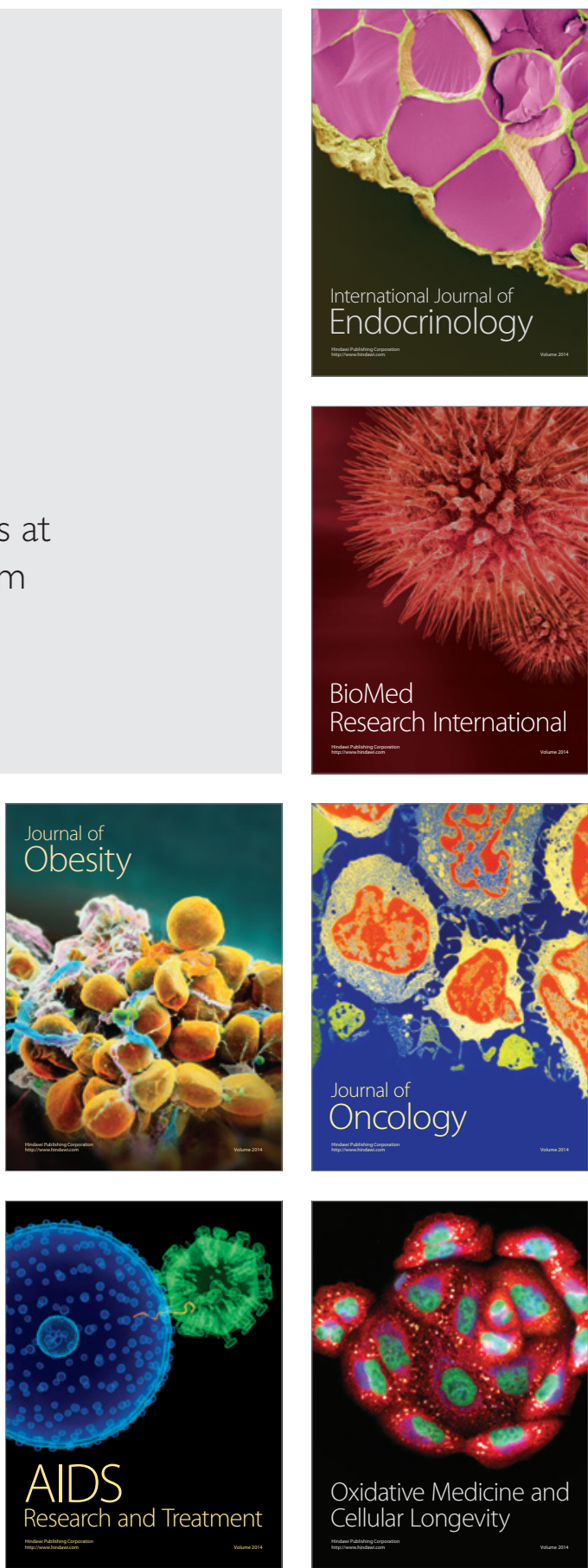